\title{
Improving slurryability, rheology, and stability of slurry fuel from blending petroleum coke with lignite
}

\author{
Jun-Hong Wu $\cdot$ Jian-Zhong Liu $\cdot$ Yu-Jie Yu $\cdot$ \\ Rui-Kun Wang $\cdot$ Jun-Hu Zhou $\cdot$ Ke-Fa Cen
}

Received: 21 August 2013/Published online: 20 January 2015

(C) The Author(s) 2015. This article is published with open access at Springerlink.com

\begin{abstract}
Petroleum coke and lignite are two important fossil fuels that have not been widely used in China. Petroleum coke-lignite slurry (PCLS), a mixture of petroleum coke, lignite, water, and additives, efficiently utilizes the two materials. In this study, we investigate the effects of the proportion $(\alpha)$ of petroleum coke on slurryability, rheological behavior, stability, and increasing temperature characteristics of PCLSs. The results show that the fixedviscosity solid concentration $\left(\omega_{0}\right)$ increases with increasing $\alpha$. The $\omega_{0}$ of lignite-water slurry (LWS, $\alpha=0$ ) is $46.7 \%$, compared to $71.3 \%$ for the petroleum coke-water slurry (PCWS, $\alpha=100 \%$ ), while that of PCLS is in between the two values. The rheological behavior of PCLS perfectly fits the power-law model. The PCWS acts as a dilatant fluid. As $\alpha$ decreases, the slurry behaves first as an approximate Newtonian fluid, and then turns into a pseudo-plastic fluid that exhibits shear-thinning behavior. With increasing $\alpha$, the rigid sedimentation and water separation ratio (WSR) increase, indicating a decrease in the stability of PCLS. When $\alpha$ is $60-70 \%$, the result is a high-quality slurry fuel for industrial applications, which has high slurryability $\left(\omega_{0}=57-60 \%\right)$, good stability (WSR $\left.<2 \%\right)$, and superior pseudo-plastic behavior $(n \approx 0.9)$.
\end{abstract}

Keywords Petroleum coke · Lignite · Coal-water slurry · Rheological characteristics $\cdot$ Slurry stability

J.-H. Wu · J.-Z. Liu (凹) · Y.-J. Yu · R.-K. Wang .

J.-H. Zhou · K.-F. Cen

State Key Laboratory of Clean Energy Utilization, Zhejiang

University, Hangzhou 310027, Zhejiang, China

e-mail: jzliu@zju.edu.cn

Edited by Yan-Hua Sun

\section{Introduction}

Petroleum coke is the main byproduct of the petroleum refining process, and it can be used for electrodes or fuel. Owing to a continuous demand for crude oil, the production of petroleum coke in China is increasing steadily (Zhou et al. 2012). Petroleum coke is a cheap fuel traditionally used as an important feedstock for circulating fluidized bed combustors because of its high calorific value, low volatile content, and high sulfur content ( $\mathrm{He}$ et al. 2011). Therefore, achieving efficient and clean utilization of petroleum coke has become an urgent issue. To this end, some utilization technologies are worthy of being explored in depth (Wu et al. 2009). One of the most efficient ways of using petroleum coke is by mixing it with water to make a slurry fuel, which is then pumped into boilers and gasifiers as feedstock for combustion and gasification (Milenkova et al. 2003; Wang et al. 2006).

One of the major problems with slurry fuels is in simultaneously maintaining the highest possible solid concentration stably and at a viscosity that is optimal for industrial application. Petroleum coke-water slurry (PCWS) has good slurryability but inferior stability because of high hydrophobic properties of petroleum coke, which can be overcome by co-slurrying of petroleum coke with lignite. Rich reserves of lignite in China-which account for up to $17 \%$ of all Chinese coal resources-have attracted increasing attention as raw material for gasification (Zhan et al. 2011). The presence of significant amounts of inherent moisture and high oxygen content in lignite renders the preparation of lignite-water slurry (LWS) difficult. In contrast, such high hydrophilicity due to the extensive numbers of oxygen functional groups is beneficial for maintaining a good and stable slurry ( $\mathrm{Yu}$ et al. 2012). Therefore, the blending of petroleum coke with 
lignite to prepare petroleum coke-lignite slurry (PCLS) can produce synergistic effects. PCLS with high-solid concentration, high calorific value, good fluidity, and excellent stability is desirable for gasification and combustion.

Abundant reports are available on the influence of blending methods on the co-combustion and co-gasification characteristics of petroleum coke and lignite. As lignite has a low calorific value and petroleum coke has low reactivity due to its low number of pores and alkali species, blending the two may potentially overcome their individual drawbacks by combining their advantages (Wang et al. 2004; Wu et al. 2009; Zhan et al. 2011). Extensive studies have been carried out to determine the factors that affect their rheological properties, such as additive types, temperature, and particle-size distribution (PSD), in order to obtain slurries with high-solid concentration, good fluidity, and sufficient stability against sedimentation of the solid particles (Goudoulas et al. 2010; Zhan et al. 2010; Gao et al. 2010, 2012). Some significant studies involving co-slurrying of low-rank coal and petroleum coke have been carried out. Vitolo et al. (1996) reported that the addition of fine pulverized petroleum coke to coal water slurry improved its rheological properties at room temperature. Recently, Yang et al. (2008) and Xu et al. (2008) have qualitatively evaluated the co-slurrying ability of petroleum coke and low-rank coal. Most efforts in the past were directed toward enhancing the slurryability of coal by mixing it with petroleum coke. However, on further examination, it seems likely that the effect of mass ratio of petroleum coke to lignite on slurrying properties has not been adequately investigated. For the sake of convenience, the mass ratio of petroleum coke to the total blend of petroleum coke and lignite samples has been defined as the petroleum coke-mixing proportion $(\alpha)$. In the present study, the effect of variable values of $\alpha$ on co-slurrying of petroleum coke and lignite was studied with respect to slurrying ability, rheological behavior, slurry stability, and the effects of increased temperature. This study aims to obtain an optimal range of $\alpha$ that is suitable for industrial application, that is, to simultaneously attain the highest solid concentration and stability at a given viscosity. The findings of this study are of great importance for the promotion of industrial applications of PCLS.

\section{Experimental}

\subsection{Materials}

XiMeng (XM), a type of Chinese lignite found in Xilingol, Inner Mongolia, China, was used for all the experiments performed in the present study. Petroleum coke samples procured from Jinshan Petrochemical Company (Shanghai,
China) were chosen for mixing with the XM lignite. The results from proximate and ultimate analysis of test samples are shown in Table 1.

Thus, the proximate and ultimate analysis results (Table 1) show huge differences between XM lignite and petroleum coke. Petroleum coke has lower oxygen content, indicating a paucity of oxygen functional groups such as hydroxyl and carboxyl, as opposed to XM lignite. Consequently, petroleum coke is hydrophobic in contrast with lignite which is hydrophilic.

Chemical additives are an important component of slurry fuels. Prior studies have demonstrated that the copolymer of methylene naphthalene-styrene sulfonatemaleate (NDF) had the best dispersing effect among the most common additives. The chemical structure of NDF additives is shown in Fig. 1. Thus, NDF was added to the PCLS preparation in this study. The additive dosage was fixed at $0.8 \mathrm{wt} \%$ based on dry coal-coke samples.

\subsection{Methods}

\subsubsection{Fourier transform infrared spectroscopy (FTIR) analysis}

FTIR analysis of the petroleum coke and lignite were carried out using a FTIR spectrophotometer (Nicolet Nexus 670, USA).

\subsubsection{Contact angle determination}

The contact angle is the angle, conventionally measured through the liquid, where a liquid/vapor interface meets a solid surface. The coal powder sample was first compressed into a cylinder with a diameter of $20 \mathrm{~mm}$ and a height of $2 \mathrm{~mm}$. A drop of water was then deposited on the coal cylinder. The dripping process was captured continuously using a high resolution camera in a contact angle measuring meter (Powereach JC2000C, Zhongchen Co., Shanghai). The photo at the moment when the water dropped onto the coal piece was selected and the contact angle between the coal and water was measured.

\subsubsection{PCLS preparation}

The raw coal and petroleum coke samples were ground with a laboratory-size ball mill, and then passed through a 100 mesh sieve to obtain experimental samples. The PSD of the sample was determined using a Mastersizer 2000 (Malvern Ltd., Britain).

PCLS preparation was standardized and used for all samples tested. At the outset, lignite, petroleum coke, distilled water, and additives were calculated and weighed in predetermined ratios. Furthermore, the weighed water 
Table 1 Proximate and ultimate analysis of petroleum coke and XM lignite

\begin{tabular}{|c|c|c|c|c|c|c|c|c|c|c|}
\hline \multirow[t]{2}{*}{ Samples } & \multicolumn{4}{|c|}{ Proximate analysis, $\%$} & \multirow[t]{2}{*}{$Q_{\mathrm{b}, \mathrm{d}}, \mathrm{MJ} / \mathrm{kg}$} & \multicolumn{5}{|c|}{ Ultimate analysis, \% } \\
\hline & $M_{\mathrm{t}}$ & $A_{\mathrm{d}}$ & $V_{\mathrm{d}}$ & $\mathrm{FC}_{\mathrm{d}}$ & & $C_{\mathrm{d}}$ & $H_{\mathrm{d}}$ & $N_{\mathrm{d}}$ & $S_{\mathrm{t}, \mathrm{d}}$ & $O_{\mathrm{d}}$ \\
\hline Petroleum coke & 0.47 & 0.43 & 10.6 & 89.0 & 36.0 & 88.6 & 3.59 & 1.11 & 5.54 & 0.74 \\
\hline XM lignite & 18.4 & 10.1 & 30.1 & 52.8 & 18.6 & 65.4 & 5.44 & 0.91 & 1.85 & 16.3 \\
\hline
\end{tabular}

$M_{\mathrm{t}}$ is the total moisture; all the following are calculated on a dry basis, $A_{\mathrm{d}}, V_{\mathrm{d}}$, and $\mathrm{FC}_{\mathrm{d}}$ refer to ash, volatiles, and fixed carbon, respectively; $S_{\mathrm{t}, \mathrm{d}}$ refers to total sulfur and $Q_{\mathrm{b}, \mathrm{d}}$ refers to the bomb calorific value

Fig. 1 Chemical structure of additive (NDF)

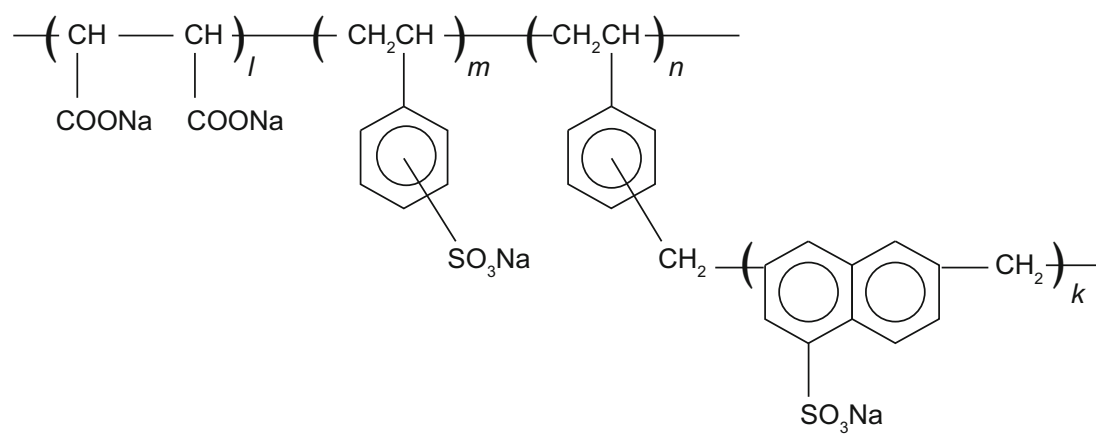

was poured into a $0.5 \mathrm{~L}$ stainless steel beaker in which the additives were completely dissolved by stirring with a mechanical mixer at $200 \mathrm{rpm}$. Subsequently, lignite and petroleum coke blends were slowly poured into the beaker, and the mixture was continuously stirred for $15 \mathrm{~min}$ at $1,000 \mathrm{rpm}$. It was necessary to allow the slurry to stand for 5 min to release the entrapped air before all measurements.

\subsubsection{Determination of PCLS properties}

The rheological behavior of the PCLSs was measured by a rotational viscometer (HAAKE VT 550, Thermo, USA). During the experiment, the temperature was maintained at $20 \pm 0.5{ }^{\circ} \mathrm{C}$ using a water bath. The apparent viscosity $\eta$ could be calculated by measuring the shear stress at a particular shear rate. The shear rate was increased from 10 to $100 \mathrm{~s}^{-1}$, and then held constant at that level for $5 \mathrm{~min}$. The viscosity data were recorded every $30 \mathrm{~s}$ during the 5 min period. The characteristic viscosity $\left(\eta_{\mathrm{c}}\right)$, defined as the apparent viscosity of the slurry sample at a shear rate of $100 \mathrm{~s}^{-1}$, was used to evaluate the slurryability. In this study, $\eta_{\mathrm{c}}$ was calculated as an average of the 10 viscosity values recorded.

The solid concentration of PCLS, $\omega$, was determined from the weight difference before and after drying in an oven at $105^{\circ} \mathrm{C}$ for $2 \mathrm{~h}$.

The effects of increasing temperature on the PCLS were considered as the apparent dependence of viscosity on the temperature. We recorded viscosity data at a fixed shear rate of $100 \mathrm{~s}^{-1}$ as we raised the temperature from 20 to $50{ }^{\circ} \mathrm{C}$.

The water separation ratio (WSR) is defined as the mass ratio of separated supernatant water to the total water in the test slurry after the slurry was left standing for 7 days. For comparison, the $\eta_{\mathrm{c}}$ of test slurry was fixed at $1,000 \mathrm{mPa} \mathrm{s}$. In the present study, the static stability of PCLS is represented by WSR. The lower the WSR, the higher is the static stability of PCLS.

\section{Results and discussion}

\subsection{Particle-size distribution}

PSD is one of the important factors in preparing high-solidconcentration slurries. A PSD for the preparation of highsolid-concentration slurries is one that allows the particle system to attain a maximum packing fraction. The PSD curves for lignite and coke samples (Fig. 2) demonstrated that the petroleum coke sample contained significant amounts of finer particles than the XM lignite sample. The volume average particle diameter was $24 \mu \mathrm{m}$ for petroleum coke and $61 \mu \mathrm{m}$ for lignite. In addition, a slight bimodal distribution of lignite could also be observed. The difference in the mean sizes of coke and coal can be effectively used to obtain a lower viscosity, because the finer particles can enter the voids between the larger particles and act as lubricants. This effect increases the relative mobility of the 


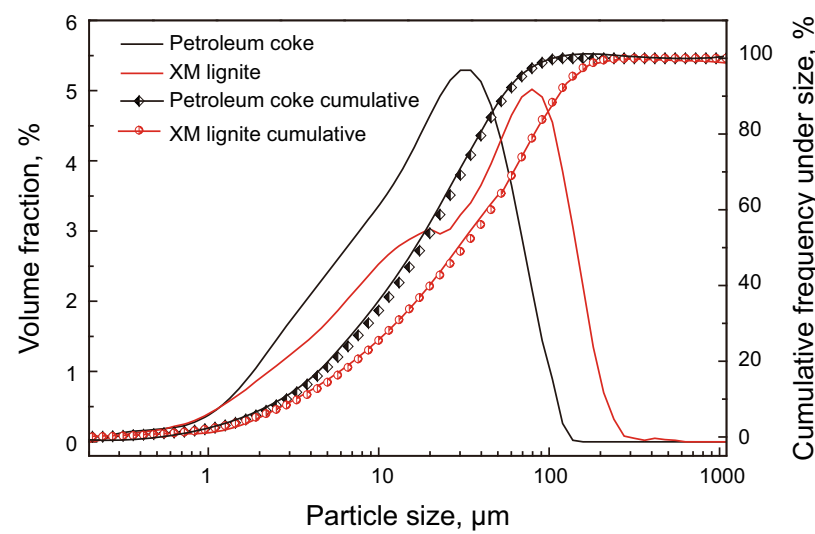

Fig. 2 Particle-size distribution of test samples

particles and decreases the viscosity of the slurry (Roh et al. 1995a, b).

\subsection{FTIR analysis}

The FTIR analysis results of the petroleum coke and lignite are shown in Fig. 3. There were two evident absorption bands, between 3,600 and $3,200 \mathrm{~cm}^{-1}$ and 1,800 and $900 \mathrm{~cm}^{-1}$ respectively. The absorption band between 3,600 and $3,200 \mathrm{~cm}^{-1}$ was attributed to $-\mathrm{OH}$ stretching vibrations of hydroxyl group. Lignite showed strong absorption intensity at this band, indicating it had more content of $-\mathrm{OH}$ group than petroleum coke. The strong peak at $1,618 \mathrm{~cm}^{-1}$ was associated with -COO- stretching vibrations of carbonyl groups, and the peak at $1,034 \mathrm{~cm}^{-1}$ was attributed to ether bonds. These peaks of lignite were also higher than that of petroleum coke, indicating lignite had higher content of oxygen functional groups.

\subsection{Contact angle}

Contact angle is one of the important indicators to measure the wettability of a surface or material. A low value of

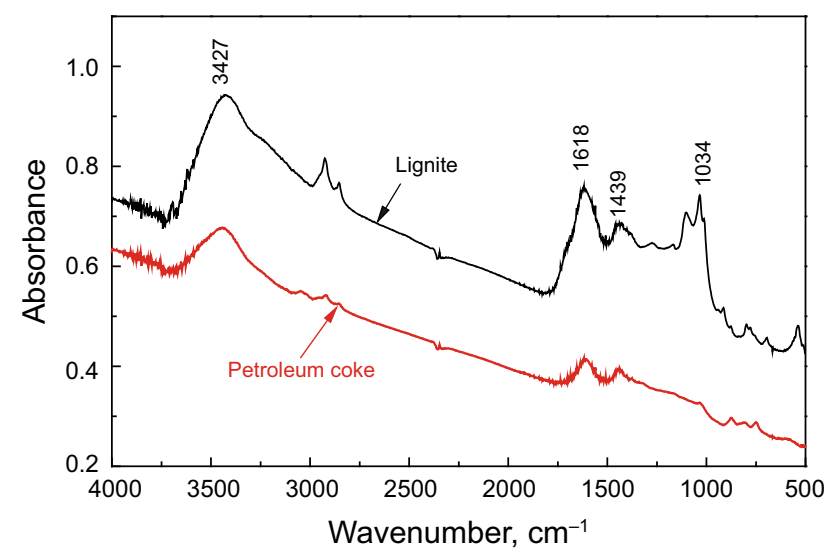

Fig. 3 FTIR spectra of test samples contact angle indicates that the liquid spreads, or wets well, while a high contact angle indicates poor wetting. The two materials had very different contact angles with water. The contact angle between petroleum coke and water was $91^{\circ}$, while that between lignite and water was only $59^{\circ}$, indicating lignite was more hydrophilic than petroleum coke. This result was consistent with FTIR analysis. Due to the high content of oxygen functional groups, the surface of lignite showed strong hydrophilicity, and thus its contact angle with water was smaller. On the contrary, petroleum coke had a hydrophobic surface, which is difficult to wet.

\subsection{Slurryability of PCLS}

Slurryability is generally measured using the fixed-viscosity solid concentration $\left(\omega_{0}\right)$, which is defined as the $\omega$ of the slurry at a given $\eta_{\mathrm{c}}$ (in this case $1,000 \mathrm{mPa} \mathrm{s}$ ). The higher the $\omega_{0}$ of a PCLS, the better is the slurryability.

The relationship between $\eta_{\mathrm{c}}$ and $\omega$ for PCLSs with various $\alpha$ values (Fig. 4) revealed that for all the cases of $\alpha$, $\eta_{\mathrm{c}}$ significantly increased with $\omega$. This observation can be explained in two possible ways. First, the force of friction between the particles becomes more significant as the number of solid particles in the slurry system increases. Second, the proportion of free water acting as a lubricant in the slurry system decreases, leading to higher viscosity.

Figure 4 also demonstrates that $\alpha$ greatly affects the $\omega_{0}$ of PCLSs. LWS $(\alpha=0)$ had a very low $\omega_{0}$ of $46.7 \%$, whereas PCWS ( $\alpha=100 \%$ ) had a high $\omega_{0}$ of $71.3 \%$. The values for $\omega_{0}$ were 50.0, 51.3, 53.2, 55.7, 57.4, 59.8, and $62.2 \%$ for PCLSs with $\alpha$ values of $20,30,40,50,60,70$, and $80 \%$, respectively. On one hand, this may be attributed to the well-developed pore structures and high surface areas in lignite. Water is adsorbed on pore surfaces and forms as pore water. Pore water cannot reduce the mutual

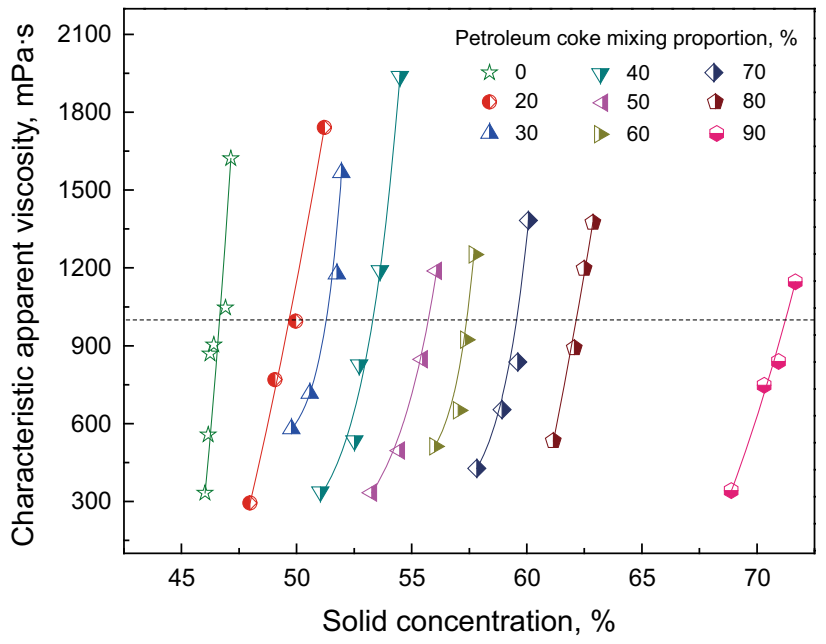

Fig. $4 \eta_{\mathrm{c}}-\omega$ dependence of PLWS with different $\alpha$ values 
friction between the solid particles like free water. As a result, lignite is difficult to use in the preparation of highly concentrated slurries. On the other hand, the content of oxygen is up to $16.3 \%$ for lignite, compared to $0.74 \%$ for petroleum coke. Lignite has a large number of hydrophilic functional groups such as $-\mathrm{COOH}$ and $-\mathrm{OH}$, resulting in absorption or trapping of large quantities of water by lignite particles. The high amount of inherent moisture cannot flow freely and is therefore unusable as a lubricant. As a result, the solid concentration of LWS $(\alpha=0)$ is low. However, petroleum coke displays perfect slurryability due to the absence of inherent moisture content. The majority of water can flow freely as lubricant. Thus, the higher the $\alpha$ value, the more mixed petroleum coke there is, which improves the slurryability of PCLSs.

\subsection{Rheological characteristics}

Rheological behavior is an important criterion of PCLSs that affects the pumping, atomizing, and combustion performance of slurry fuels. Therefore, good rheological characteristics are of great importance for the industrial application of PCLSs. A PCLS is a two-phase solid-liquid fluid, and the rheological characteristics of PCLSs can be described by the power-law model (Roh et al. 1995a, b):

$\tau=K \cdot \gamma^{n}$

where $\tau$ is the shear stress, $\mathrm{Pa}$; $K$ is the consistency coefficient, $\mathrm{Pa} s^{n} ; \gamma$ is the shear rate, $\mathrm{s}^{-1}$; and $n$ is the rheological index (dimensionless). For a Newtonian fluid, $n=1$; for a dilatant fluid, $n>1$; for a pseudo-plastic fluid, $n<1$.

\subsubsection{Rheological characteristics of LWS $(\alpha=0)$}

The rheological behavior curves for LWS (Fig. 5) show that shear-thinning behavior $(n<1)$ can be observed for LWS, implying that LWS can be regarded as a pseudoplastic fluid. It has been confirmed that a reticular threedimensional network structure is formed through hydrogen bonds and dipolar polar groups that bind large amounts of water on the surfaces of lignite particles. In addition, the surfaces of solid particles combined with additives form hydration shells. Thus, LWS has high viscosity and good stability under static conditions. Upon being sheared, the reticular structure of the LWS is destroyed and then part of the water is released as a lubricant. Thus, the viscosity decreases as the shear rate increases owing to the lowering of the friction between the particles, and LWS shows features of a pseudo-plastic fluid (Yang et al. 2008; Zhu et al. 2003).

As shown in Table 2, the solid concentration had a great influence on the rheological index $n$ of LWS. With
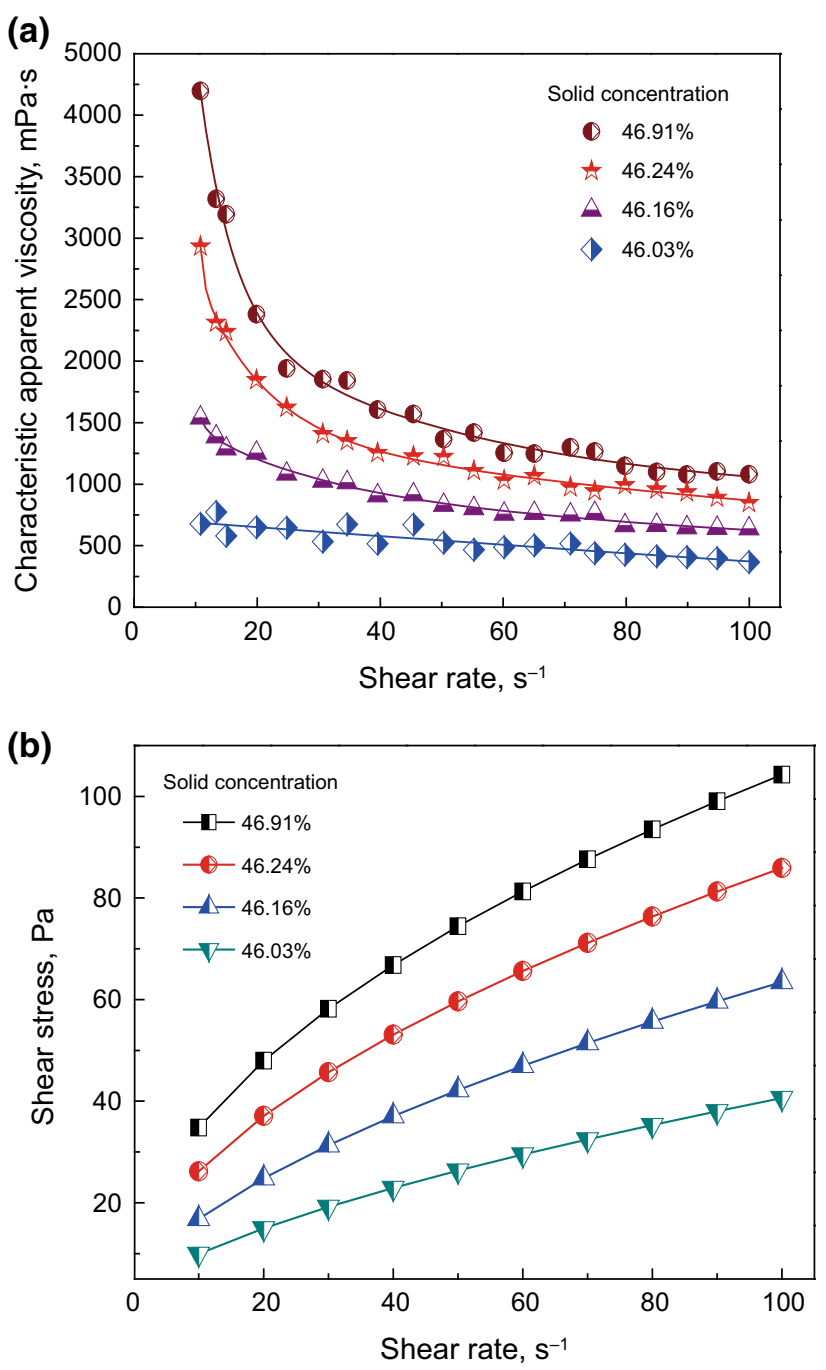

Fig. 5 Rheological properties of LWS. a Apparent viscosity versus shear rate $(\alpha=0)$. b Shear stress versus shear rate $(\alpha=0)$

Table 2 Parameters of rheological model for LWS

\begin{tabular}{lccll}
\hline$\omega, \mathrm{wt} \%$ & $\eta_{\mathrm{c}}, \mathrm{mPa} \mathrm{s}$ & $K, \mathrm{~Pa} \mathrm{~s}^{n}$ & $n$ & $R^{2}$ \\
\hline 46.03 & 332 & 2.20 & 0.633 & 0.896 \\
46.24 & 557 & 4.07 & 0.596 & 0.989 \\
46.16 & 904 & 7.38 & 0.533 & 0.983 \\
46.91 & 1,047 & 10.78 & 0.493 & 0.956 \\
\hline
\end{tabular}

increasing concentration, the value of $n$ gradually decreased, indicating shearing had a greater influence on the viscosity at higher solid concentration. It is because that greater changes in interior structure of higher solid concentration slurry occur when the slurry is subjected to shear, mainly in the following two aspects: on the one hand, when the solid concentration increases, the amounts of solid particles significantly increase, then more clusters 
of "water in coal" are formed in the slurry when the coal particles link and coagulate with each other during the preparation process, but the clusters could be deformed and broken up easily when subjected to shear, and then the enclosed water is released (Wang et al. 2011). On the other hand, high speed shearing induces directional migration of particles, and the fine particles fill the interspace of the coarse particles. Consequently, a rigid microstructure assembled by particles is produced, i.e., the maximum packing fraction $\Phi_{\mathrm{m}}$ increases with the shearing force. Based on the research of Wildemuth and Williams (1984), the viscosity of slurry declines with increasing $\Phi_{\mathrm{m}}$.

\subsubsection{Rheological characteristics of PCWS $(\alpha=100 \%)$}

The rheological behavior curves for PCWS (Fig. 6) show that shear-thickening behavior $(n>1)$ is observed,

\section{(a)}

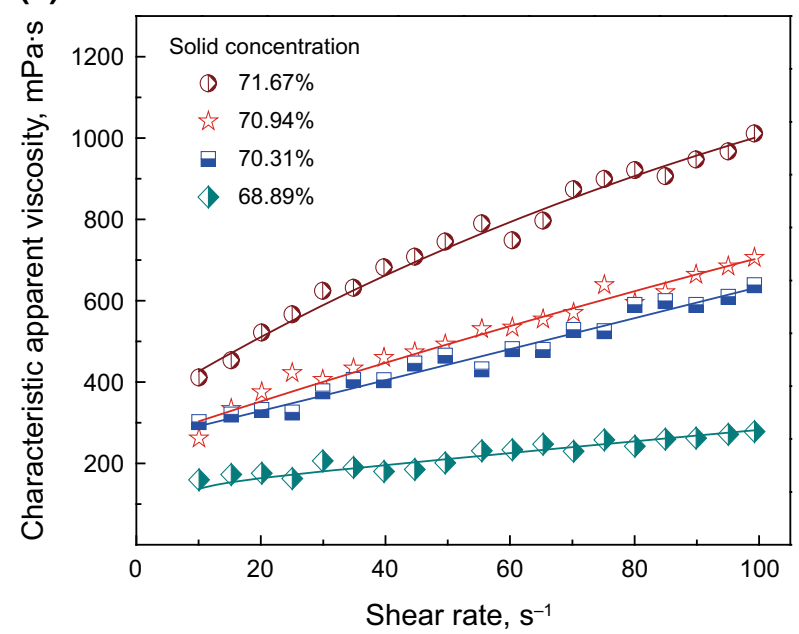

(b)

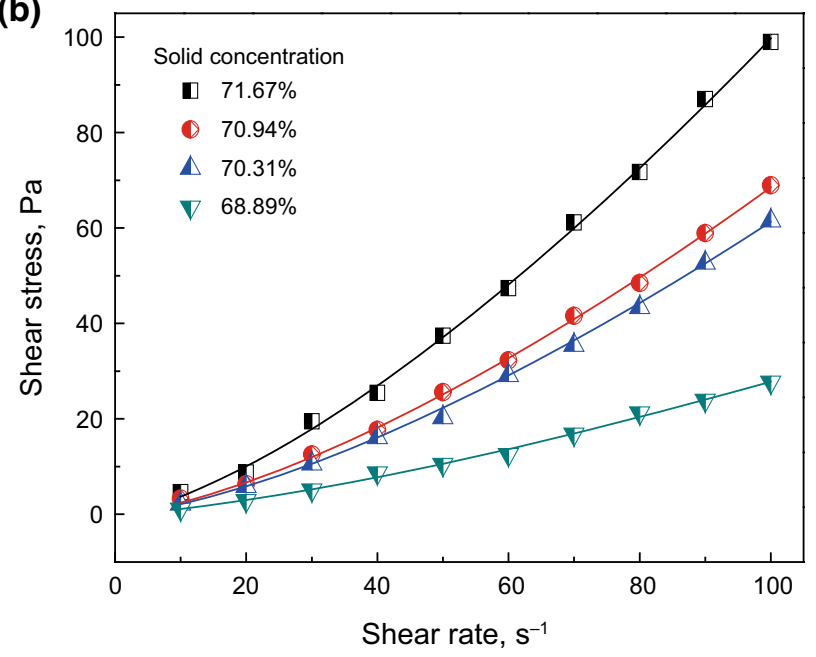

Fig. 6 Rheological properties of PCWS $(\alpha=100 \%)$. a Apparent viscosity versus shear rate $(\alpha=100 \%)$. b Shear stress versus shear rate $(\alpha=100 \%)$
Fig. 7 Rheological properties of PCLSs. a Apparent viscosity versus shear rate $(\alpha=20 \%)$. b Shear stress versus shear rate $(\alpha=20 \%)$. c Apparent viscosity versus shear rate $(\alpha=30 \%)$. d Shear stress versus shear rate $(\alpha=30 \%)$. e Apparent viscosity versus shear rate $(\alpha=40 \%)$. f Shear stress versus shear rate $(\alpha=40 \%)$. g Apparent viscosity versus shear rate $(\alpha=50 \%)$. h Shear stress versus shear rate $(\alpha=50 \%)$. i Apparent viscosity versus shear rate $(\alpha=60 \%)$. j Shear stress versus shear rate $(\alpha=60 \%)$. k Apparent viscosity versus shear rate $(\alpha=70 \%)$. I Shear stress versus shear rate $(\alpha=70 \%)$. m Apparent viscosity versus shear rate $(\alpha=80 \%)$. n Shear stress versus shear rate $(\alpha=80 \%)$

indicating that PCWS is a dilatant fluid. This is because the inter-particle forces keep the petroleum coke particles with hydration shells in an ordered structure under static conditions. Thus, the PCWS shows good fluidity. At a higher shear rate, the shear forces attain larger magnitudes than the inter-particle forces. Consequently, the hydration shell ruptures and petroleum coke particles easily aggregate because of their mutual attraction, causing an increase in viscosity and confirming that PCWS is a dilatant fluid.

Table 3 shows the rheological parameters with different solid concentrations for PCWS. The rheological index $n$ changed slightly, but the consistency coefficient $K$ increased with concentration. At a low concentration, the apparent viscosity $\eta$ was relatively low and changed slightly when the shear rate $\gamma$ was increased. At a high concentration, the viscosity of PCWS increased strongly with the shear rate.

\subsubsection{Effect of $\alpha$ on rheological characteristics of PCLSs}

The rheological characteristics are quite different when lignite and petroleum coke are used to make slurry. Mixing petroleum coke with lignite for preparing PCLS is an effective way to use these two fuels. The rheological behavior curves for PCLSs at different values of $\alpha$ (Fig. 7) and the rheological model parameters of PCLSs (Table 4) show that the consistency coefficient $K$ depended on $\omega$ and $\alpha$, and $\eta_{\mathrm{c}}$ was strongly related to $K$, and that $\alpha$ highly influenced the rheological characteristics of PCLSs. Increasing the value of $\alpha$ clearly led to an increase in the value of $n$, indicating that on adding high quantities of lignite, the pseudo-plastic behavior of PCLSs became more obvious. The PCLSs exhibited pseudo-plastic behavior even for $\alpha$ in the range of $60-70 \%$. When more petroleum

Table 3 Parameters of rheological model for PCWS $(\alpha=100 \%)$

\begin{tabular}{lllll}
\hline$\omega, \mathrm{wt} \%$ & $\eta_{\mathrm{c}}, \mathrm{mPa} \mathrm{s}$ & $K, \mathrm{~Pa} \mathrm{~s}^{n}$ & $n$ & $R^{2}$ \\
\hline 68.89 & 342 & 0.04 & 1.404 & 0.992 \\
70.31 & 748 & 0.07 & 1.469 & 0.995 \\
70.94 & 839 & 0.07 & 1.489 & 0.994 \\
71.67 & 1,146 & 0.13 & 1.445 & 0.996 \\
\hline
\end{tabular}


(a)

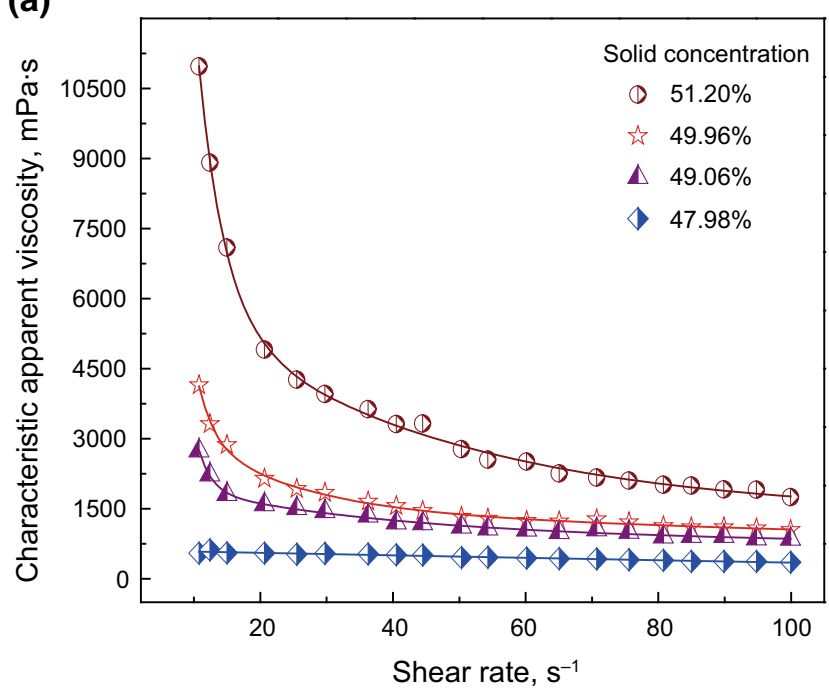

(c)

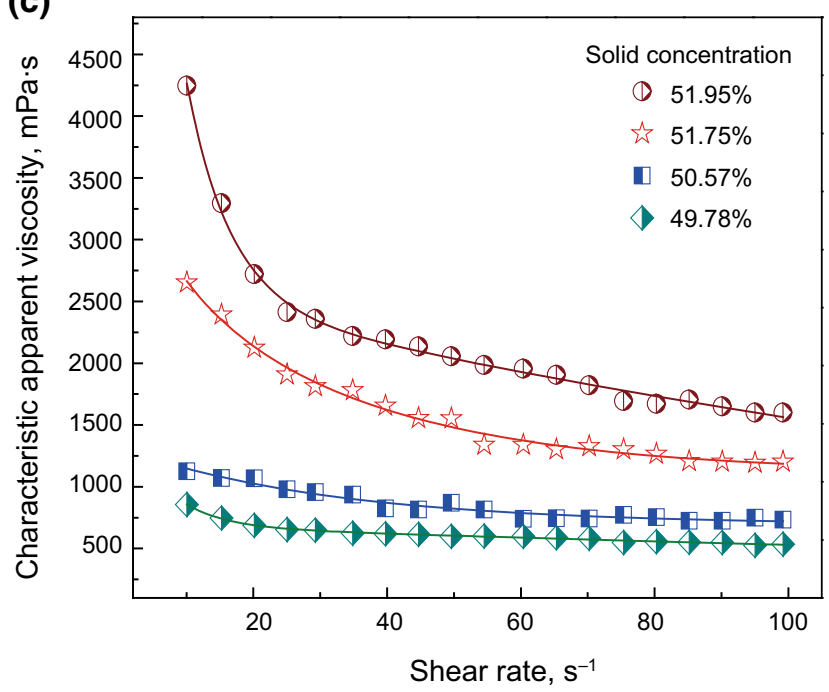

(e)

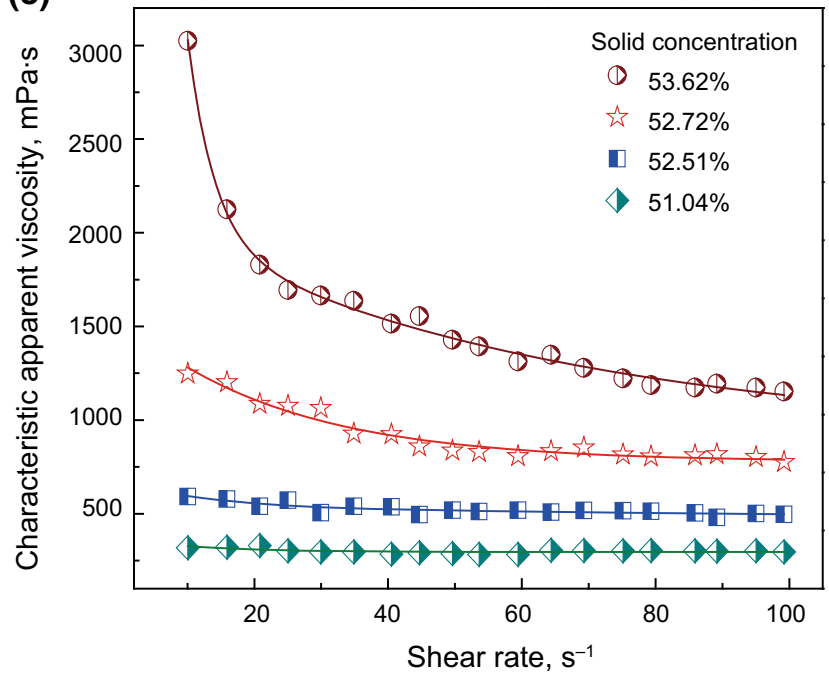

(b)

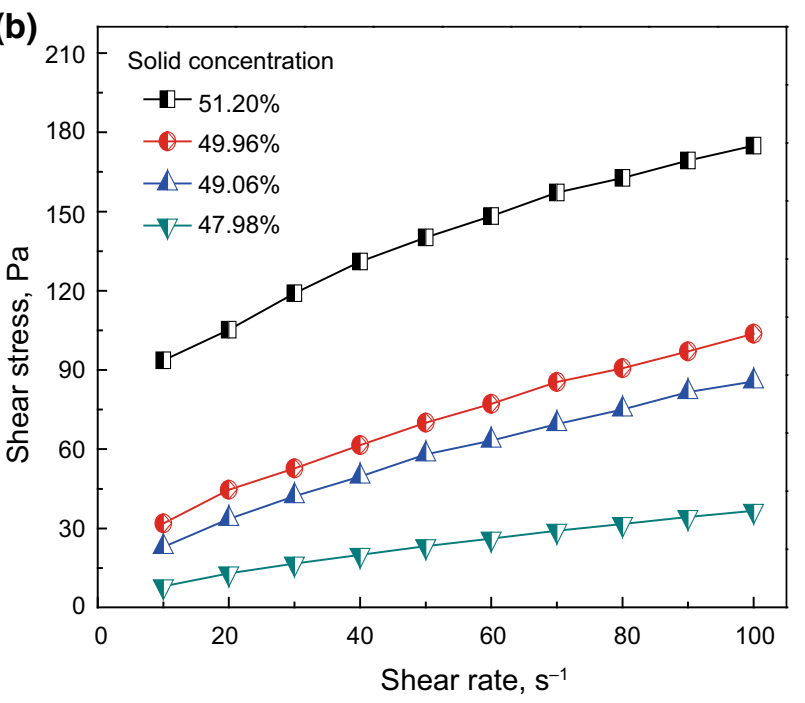

(d)
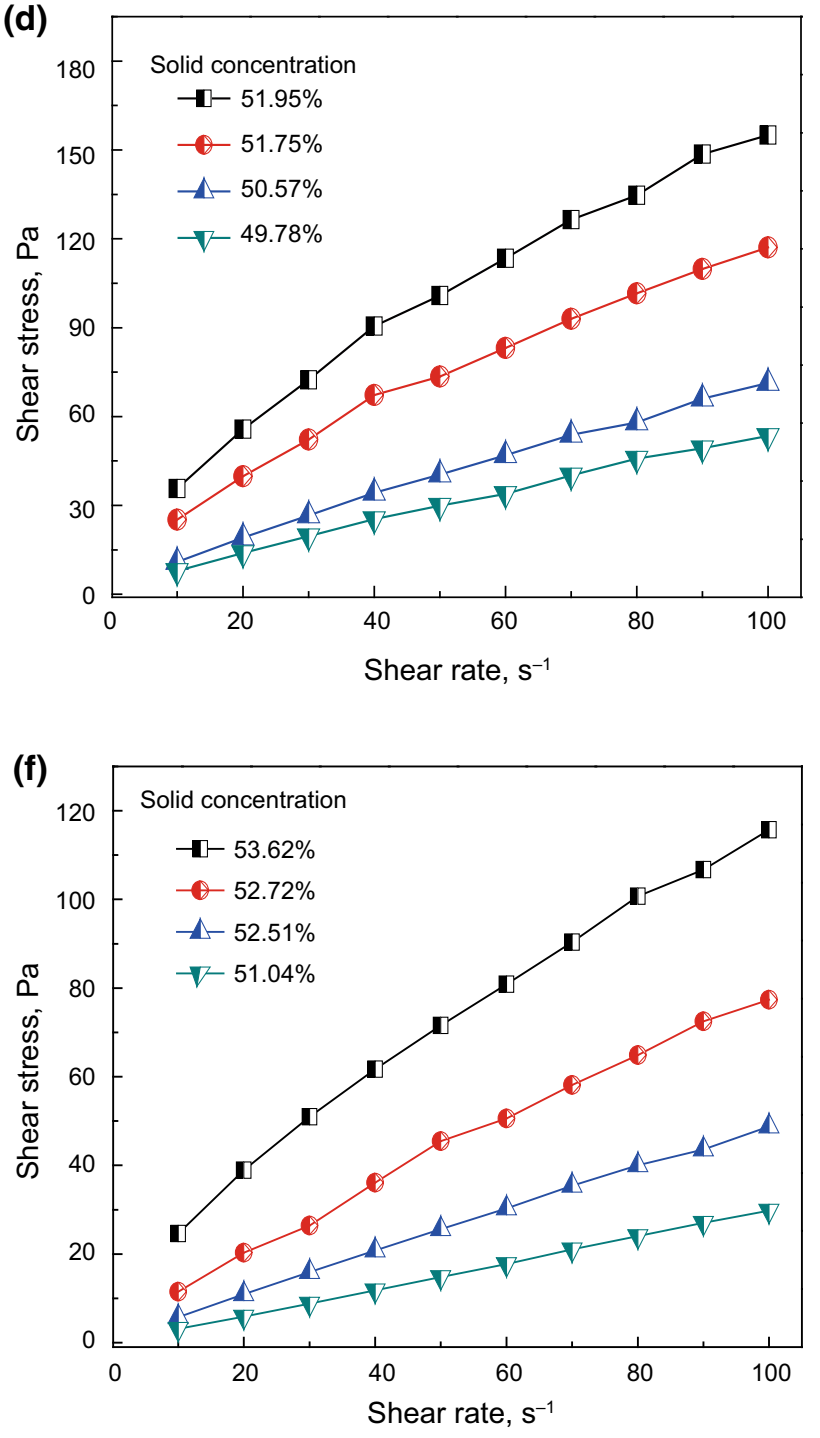
(g)
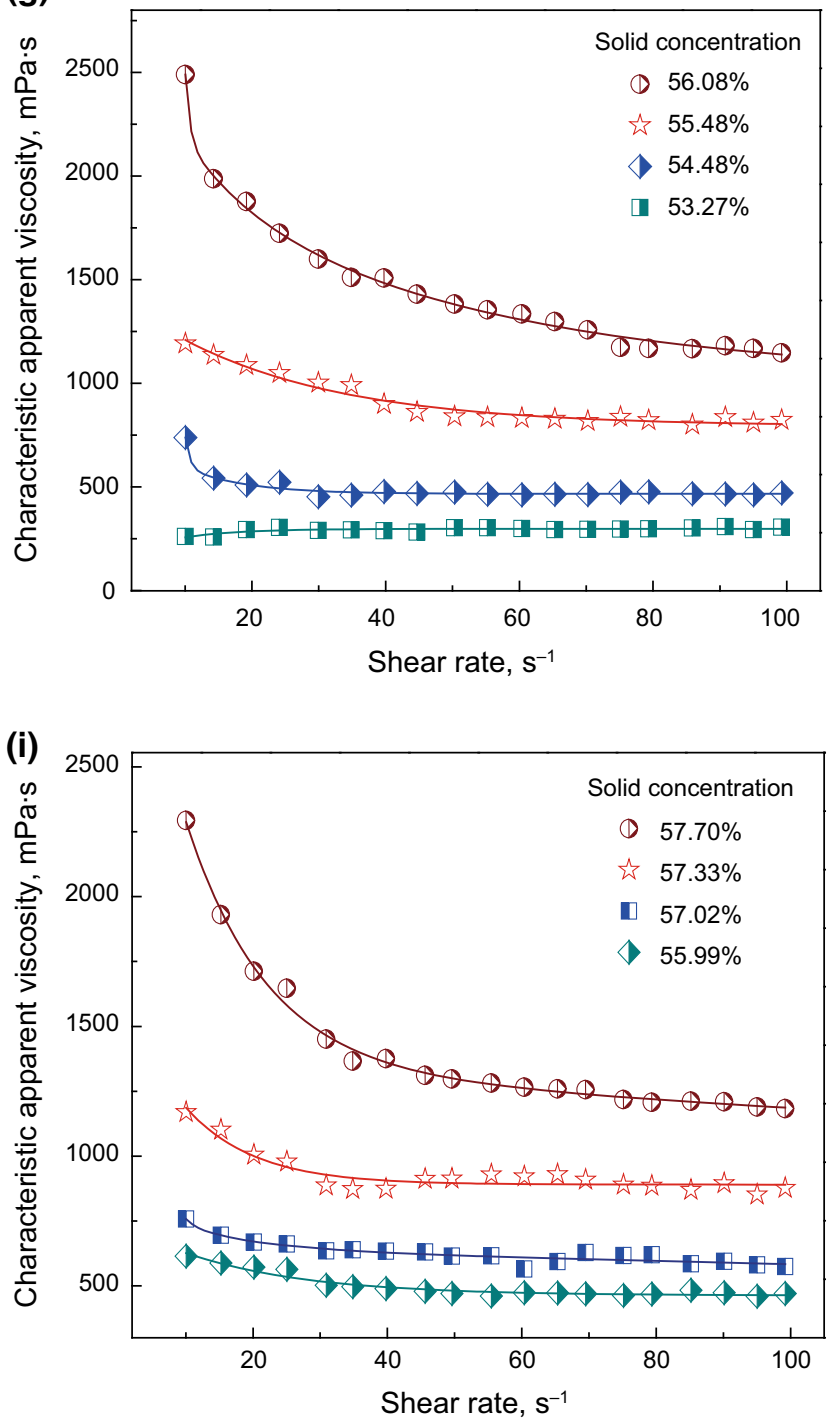

(k)

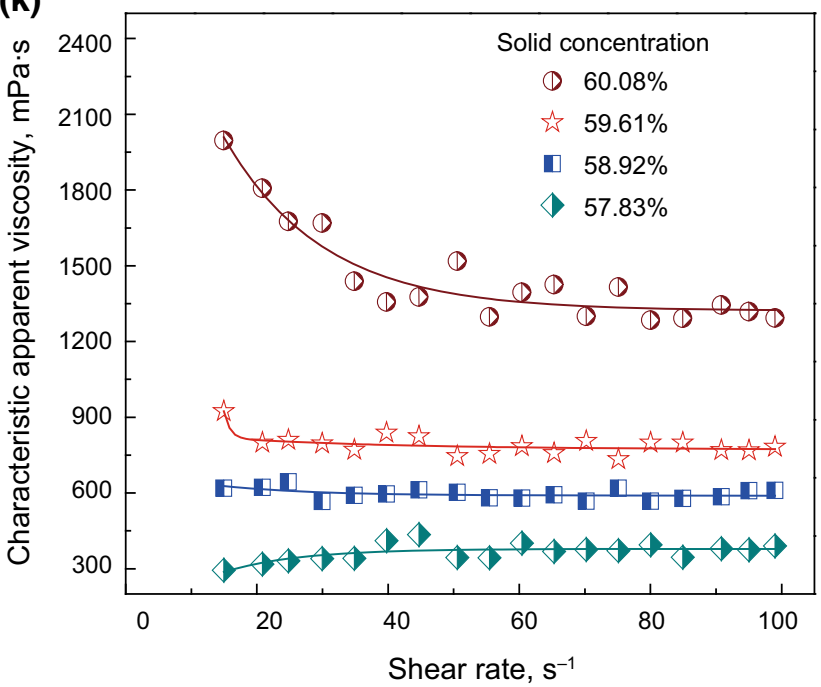

(h)

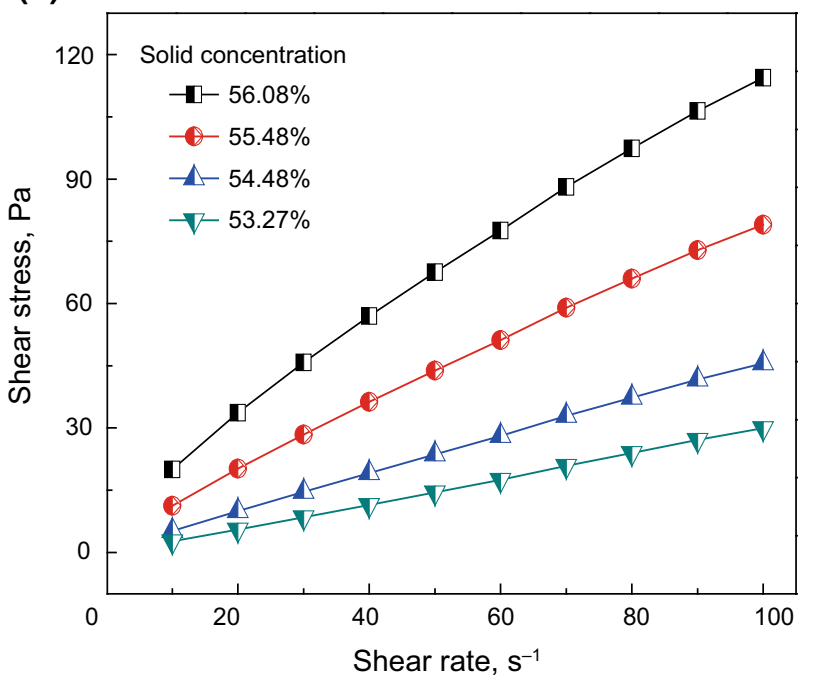

(j)

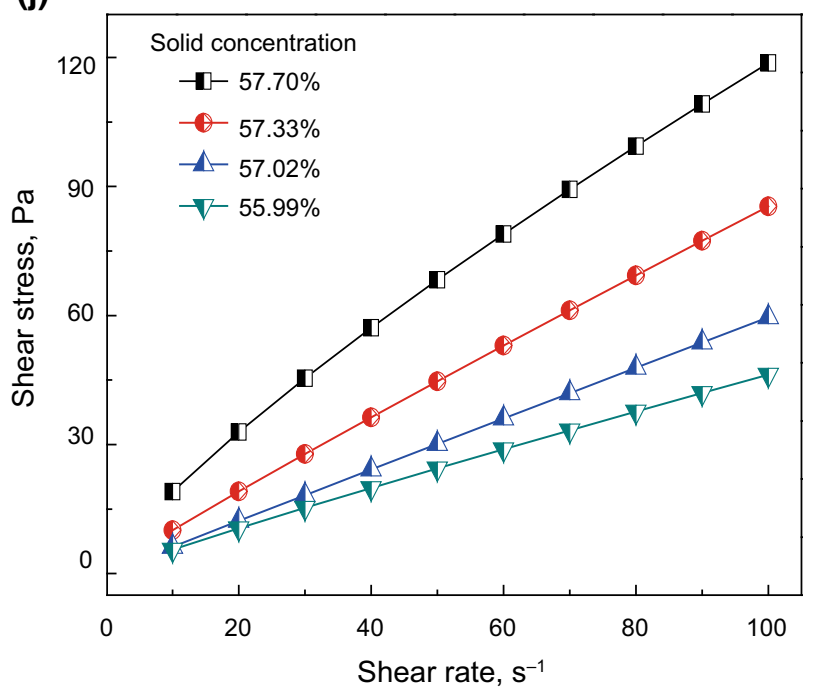

(I)

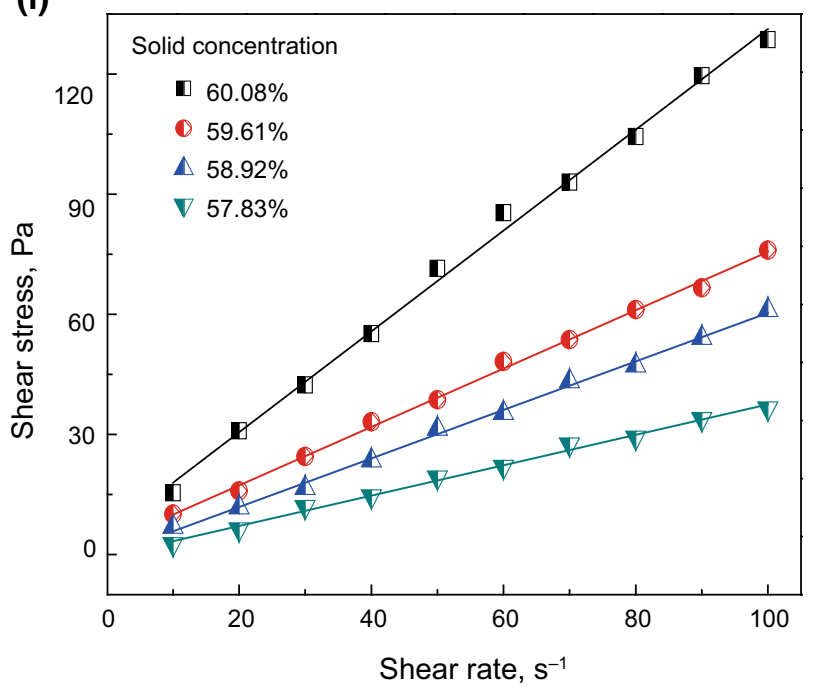

Fig. 7 continued 


\section{(m)}

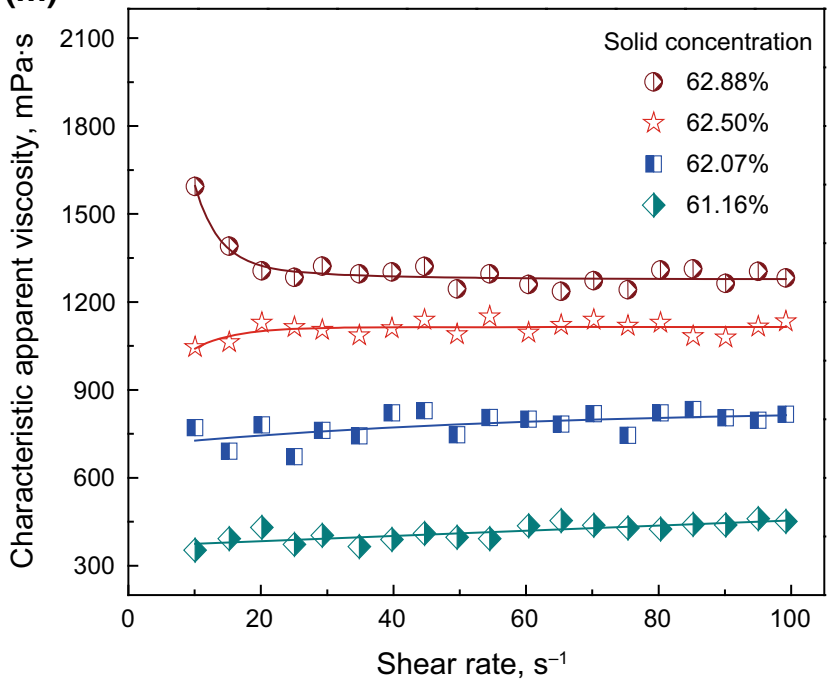

(n)

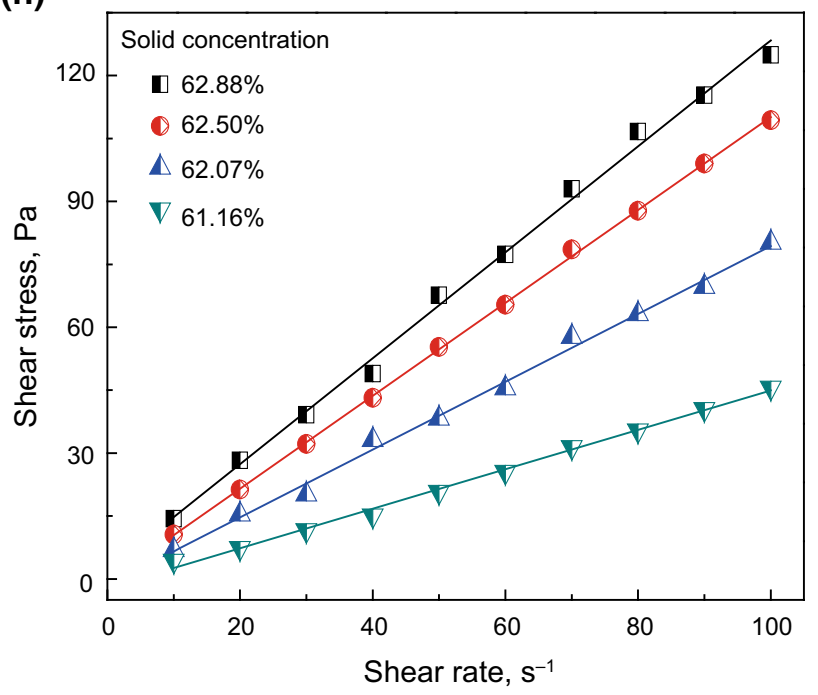

Fig. 7 continued

Table 4 Parameters of the rheological model for PCLSs

\begin{tabular}{|c|c|c|c|c|c|}
\hline$\alpha, \mathrm{wt} \%$ & $\omega, \mathrm{wt} \%$ & $\eta_{\mathrm{c}}, \mathrm{mPa} \mathrm{s}$ & $K, \mathrm{~Pa} \mathrm{~s}^{n}$ & $n$ & $R^{2}$ \\
\hline \multirow[t]{4}{*}{20} & 47.98 & 293 & 1.78 & 0.657 & 0.986 \\
\hline & 49.06 & 768 & 5.60 & 0.592 & 0.986 \\
\hline & 49.96 & 994 & 7.90 & 0.557 & 0.984 \\
\hline & 51.20 & 1,741 & 39.69 & 0.322 & 0.985 \\
\hline \multirow[t]{4}{*}{30} & 49.78 & 579 & 1.14 & 0.837 & 0.998 \\
\hline & 50.57 & 716 & 1.64 & 0.821 & 0.992 \\
\hline & 51.75 & 1,177 & 5.34 & 0.672 & 0.994 \\
\hline & 51.95 & 1,567 & 7.95 & 0.650 & 0.991 \\
\hline \multirow[t]{4}{*}{40} & 51.04 & 337 & 0.28 & 1.013 & 0.997 \\
\hline & 52.51 & 534 & 0.67 & 0.933 & 0.996 \\
\hline & 52.72 & 827 & 1.67 & 0.834 & 0.989 \\
\hline & 53.62 & 1,191 & 5.24 & 0.669 & 0.990 \\
\hline \multirow[t]{4}{*}{50} & 53.27 & 333 & 0.23 & 1.055 & 0.998 \\
\hline & 54.48 & 495 & 0.58 & 0.951 & 0.996 \\
\hline & 55.48 & 847 & 1.57 & 0.852 & 0.992 \\
\hline & 56.08 & 1,188 & 3.43 & 0.763 & 0.988 \\
\hline \multirow[t]{4}{*}{60} & 55.99 & 513 & 0.67 & 0.923 & 0.991 \\
\hline & 57.02 & 651 & 0.64 & 0.987 & 0.994 \\
\hline & 57.33 & 923 & 1.16 & 0.934 & 0.991 \\
\hline & 57.70 & 1,251 & 3.00 & 0.800 & 0.989 \\
\hline \multirow[t]{4}{*}{70} & 57.83 & 427 & 0.37 & 1.003 & 0.973 \\
\hline & 58.92 & 654 & 0.57 & 1.009 & 0.995 \\
\hline & 59.61 & 838 & 0.85 & 0.978 & 0.993 \\
\hline & 60.08 & 1,383 & 2.59 & 0.850 & 0.989 \\
\hline \multirow[t]{4}{*}{80} & 61.16 & 534 & 0.24 & 1.138 & 0.995 \\
\hline & 62.07 & 892 & 0.58 & 1.072 & 0.992 \\
\hline & 62.50 & 1,198 & 0.99 & 1.026 & 0.989 \\
\hline & 62.88 & 1,375 & 1.37 & 0.987 & 0.991 \\
\hline
\end{tabular}

coke was added, the PCLSs (when $\alpha>70 \%$ ) exhibited the rheological characteristics of an approximate Newtonian fluid ( $n=1)$.

With increasing solid concentration, the value of $n$ gradually decreased, indicating the pseudo-plastic behavior of slurry was enhanced (such as $\alpha=30 \%$ ), or the flow behavior of slurry was changed from dilatant to pseudo-plastic (such as $\alpha=70 \%$ ). It is because that as solid concentration is increased, the changes in interior structure of the slurry become more prominent when the slurry is sheared at a high speed. The detailed explanations are shown in Sect. 3.5.1.

When $\alpha \leq 70 \%$, the pseudo-plastic behavior of PCLS matched well with the requirements of industrial applications. The sedimentation of solid particles was effectively restrained because of high viscous force and friction under static storage of PCLSs. As a result, the stability of slurry fuel was enhanced. However, the viscosity of slurry declined a lot during the pumping and atomizing processes, which is beneficial for cost reduction.

\subsection{Effect of temperature}

Temperature has a considerable influence on the properties of the slurry. In general, the slurry is preheated prior to combustion or gasification to obtain optimal atomization effects, and the viscosity of the slurry is expected to decrease as the temperature rises. The relationship between $\eta$ and temperature $(T)$ at varying values of $\alpha(30,50$, and $70 \%$ ) is presented in Fig. 8, from which it can be observed that the value of $\eta$ consistently decreased as the temperature increased from 20 to $50{ }^{\circ} \mathrm{C}$, with a concomitant drop 

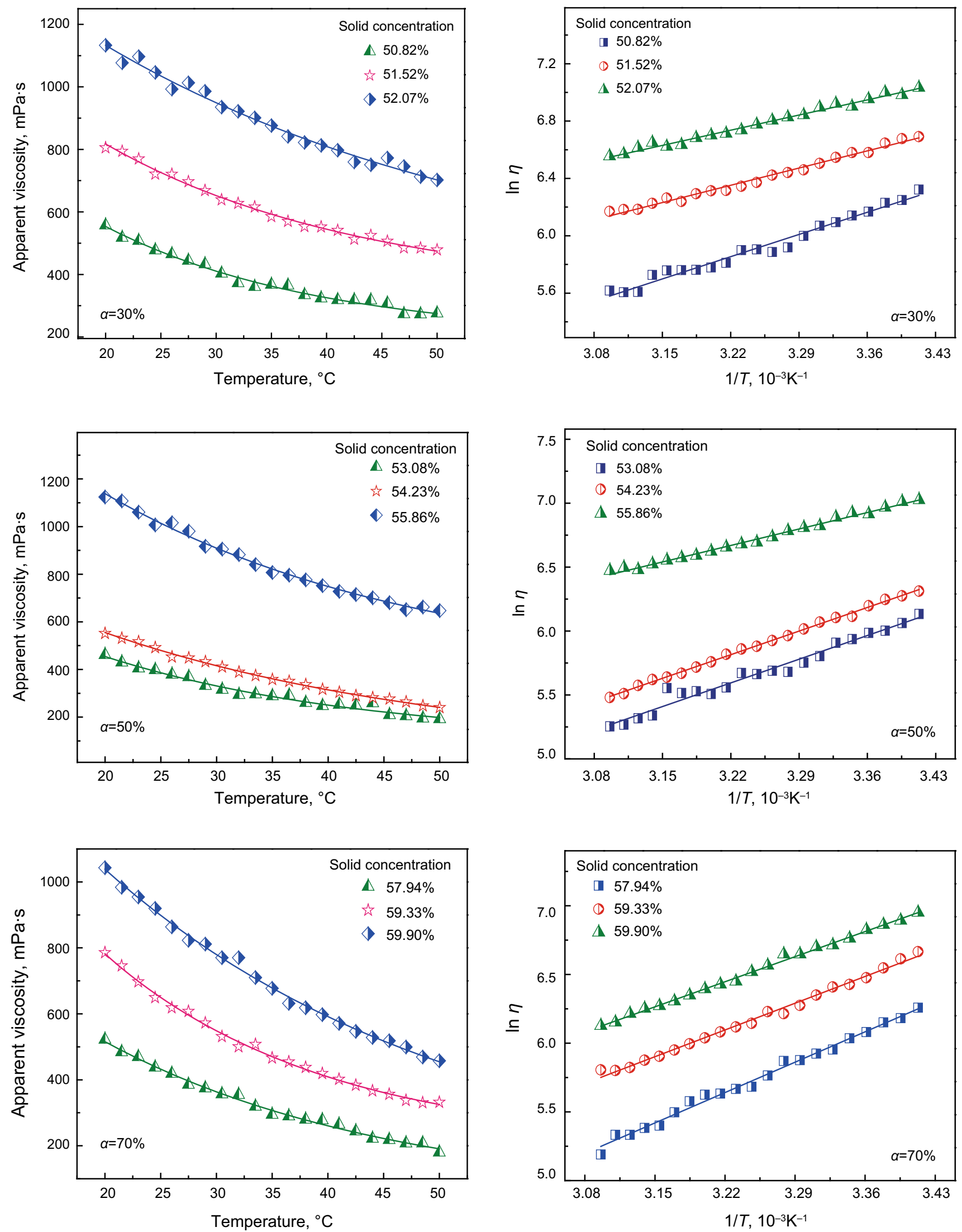

Fig. 8 Effect of temperature on apparent viscosity 
in viscosity of up to $60 \%$. For example, the value of $\eta$ sharply decreased from $1,043 \mathrm{mPa} \mathrm{s}$ to $457 \mathrm{mPa} \mathrm{s}$ at $\alpha=70 \%$ and $\omega=59.9 \%$. This phenomenon can be attributed to a combination of several factors (Chen et al. 2008; Roh et al. 1995a, b). Primarily, the liquid phase in the PCLS system, essentially free water, possesses good viscosity-reducing properties with increasing temperature, which is the main cause of the decrease in the viscosity of PCLS. Second, as the temperature is increased, the effects of additives that make coal particles more easily dispersed are enhanced. In addition, an increase in the temperature of the system leads to an increase in the kinetic energy of the particles, resulting in their further dispersion and consequent reduction in the value of $\eta$.

Earlier studies have described the general consensus about the relationship between $\eta$ and $T$ in terms of a simple Arrhenius expression for the range of temperatures investigated (Mishra et al. 2002):

$\eta=A \cdot \exp (E / R T)$

Or

$\ln \eta=E / R T+\ln A$,

where $\eta$ is the viscosity; $E$ is the fluid-flow activation energy; $T$ is the temperature in Kelvin; $R$ is the universal gas constant; and $A$ is a fitting parameter.

As indicated in Fig. $8, \ln (\eta)$ was approximately linear with $1 / T$, which implies that the influence of temperature on the viscosity of PCLS is in good agreement with the Arrhenius equation. Table 5 presents the parameters of the Arrhenius correlation for PCLSs with varying $\omega$ values. Notably, the value of $A$ rapidly increases with concentration at a constant value of $\alpha$. This suggests that the value of

Table 5 Parameters for Arrhenius correlation of PCLSs

\begin{tabular}{lllll}
\hline$\alpha, \mathrm{wt} \%$ & $\omega, \mathrm{wt} \%$ & $E, \mathrm{~kJ} \mathrm{~mol}^{-1}$ & $A, \mathrm{mPa} \mathrm{s}$ & $R^{2}$ \\
\hline 30 & 50.82 & 18.99 & 0.223 & 0.980 \\
& 51.52 & 14.58 & 2.025 & 0.988 \\
& 52.07 & 12.62 & 6.346 & 0.986 \\
50 & 53.08 & 22.21 & 0.049 & 0.977 \\
& 54.23 & 21.85 & 0.071 & 0.997 \\
& 55.86 & 15.51 & 1.939 & 0.992 \\
70 & 57.94 & 26.13 & 0.011 & 0.994 \\
& 59.33 & 23.77 & 0.045 & 0.993 \\
& 59.90 & 21.61 & 0.147 & 0.996 \\
\hline
\end{tabular}

$A$ can indicate the concentration of the slurry to some extent. The value of $E$ varies little, suggesting that the fluid-flow activation energy is almost uninfluenced by concentration. The fluid-flow activation energy $E$ refers to the energy needed for particles to overcome the interaction of surrounding molecules and flow into free space, and more importantly, it shows how susceptible viscosity is to changes in temperature. The higher the value of $E$, the more sensitive viscosity is to variations in temperature. Moreover, the value of $E$ increases with the value of $\alpha$, which implies that the sensitivity of viscosity to temperature increases with the proportion of petroleum coke.

\subsection{Stability properties of PCLS}

Stability is an important feature in the quality of PCLS, which determines its efficacy and employability in largescale industrial applications. In this study, all the slurry samples were allowed to stand, and the water separation and sedimentation were evaluated to assess the stability. It was observed that $\alpha$ highly influenced the sedimentation of PCLSs. Thus, for $\alpha$ in the range of $0-70 \%$, soft sedimentation was observed at the bottom of the slurry within $72 \mathrm{~h}$, which could be reverted to the initial slurry by agitation even after 7 days. Nevertheless, rigid sedimentation, which could not be reverted to a uniform suspension by agitation, was engendered in PCLSs for $\alpha \geq 70 \%$.

We measured WSR (Table 6) to evaluate the static stability of each PCLS. The WSR was below $6 \%$ for all $\alpha$ values. Furthermore, the stability tended to be better for low $\alpha$ PCLSs: the lower the value of $\alpha$, the lower the WSR (the better the stability). Significantly, the WSR rapidly increased for $\alpha \geq 70 \%$, which could be explained as follows. The higher the lignite content, the better the stability of the reticular three-dimensional structure. In contrast, the higher the content of petroleum coke added to PCLS, the more obvious the extent of sedimentation and water separation. A high content of petroleum coke reduced the stability, which can be attributed to the highly hydrophobic surface of petroleum coke that can easily lead to substantial aggregation of particles.

\subsection{The optimal value of $\alpha$}

When $\alpha$ increases, the PCLS exhibits better slurryability, but poorer rheological properties and stability. By considering all the factors, the optimal value of $\alpha$ for industrial

Table 6 WSR of PCLSs maintained for 7 days

\begin{tabular}{llllllllll}
\hline$\alpha, \mathrm{wt} \%$ & 0 & 20 & 30 & 40 & 50 & 60 & 70 & 80 & 100 \\
\hline WSR, $\%$ & 0 & 0 & 0.469 & 0.629 & 1.423 & 1.641 & 1.971 & 4.049 & 5.733 \\
\hline
\end{tabular}


applications is between $60 \%$ and $70 \%$. Thus, a highquality slurry fuel with high slurryability $(\omega=57-60 \%)$, good stability (WSR $<2 \%$ ), and superior pseudo-plastic behaviors $(n \approx 0.9$ ) can be produced.

\section{Conclusions}

Petroleum coke and lignite are promising fuels that have different slurrying characteristics. The strongly hydrophobic surface of petroleum coke can enhance the solid concentration of the slurry, but leads to poor stability. In contrast, the high content of inner moisture and the presence of oxygen functional groups in lignite reduce its usefulness in preparing high-concentration slurries, but impart lignite with a three-dimensional network structure that provides both fluidity and stability. In our study, we verified that mixing petroleum coke with lignite in PCLS combines their complementary strengths to make PCLS useful for combustion and gasification. The main conclusions are as follows:

(1) The fixed-viscosity solid concentration $\left(\omega_{0}\right)$ of PCLS positively correlates with $\alpha$. The $\omega_{0}$ of LWS $(\alpha=0)$ is $46.7 \%$ compared to $71.3 \%$ for PCWS $(\alpha=100 \%)$. PCLSs have $\alpha$ values between those of LWS and PCWS. The characteristic apparent viscosity $\eta_{\mathrm{c}}$ increases with $\omega$. Mixing fine petroleum coke with coarse lignite is conducive to improving the slurryability of PCLS.

(2) The rheological behavior of PCLS perfectly fits the power-law model. LWS performs as a pseudo-plastic fluid. As $\alpha$ increases, the slurry behaves as an approximate Newtonian fluid, and then turns to a dilatant fluid, which exhibits shear-thickening behavior. As $\omega$ increases, the consistency coefficient $K$ increases, while the rheological index $n$ decreases.

(3) The $\eta_{\mathrm{c}}$ of PCLS decreases as temperature increases. The viscosity drops by up to $60 \%$ as temperature increases from 20 to $50{ }^{\circ} \mathrm{C}$. The fluid-flow activation energy $E$ increases with $\alpha$, indicating that viscosity becomes more sensitive to decrease as temperature increases.

(4) LWS $(\alpha=0)$ provides good stability without water separation and rigid sedimentation. As more petroleum coke is added, the rigid sedimentation and WSR increase, lowering the stability of PCLS.

(5) After considering all of the parameters that we studied, including slurryability, fluidity, and stability of PCLS, the optimal value of $\alpha$ for industrial applications is $60-70 \%$. At this concentration of petroleum coke, a high-quality slurry fuel with high slurryability $(\omega=57-60 \%)$, good stability
(WSR $<2 \%$ ), and superior pseudo-plastic behaviors $(n \approx 0.9)$ can be produced.

Acknowledgments The authors acknowledge the financial support provided by the National Basic Research Program of China (Grant No. 2010CB227001).

Open Access This article is distributed under the terms of the Creative Commons Attribution License which permits any use, distribution, and reproduction in any medium, provided the original author(s) and the source are credited.

\section{References}

Chen LY, Duan YF, Liu M, et al. True rheological behavior of coalwater slurry. J Power Eng. 2008;28(5):753-8 (in Chinese).

Gao FY, Liu JZ, Wang CC, et al. Effects of the physical and chemical properties of petroleum coke on its slurryability. Pet Sci. 2012;9(2):251-6.

Gao FY, Liu JZ, Wang CC, et al. Slurryability of petroleum coke and rheological characteristics and stability of PCWS. CIESC J. 2010;61(11):2912-8 (in Chinese).

Goudoulas TB, Kastrinakis EG, Nychas SG. Preparation and rheological characterization of lignite-water slurries. Energy Fuels. 2010;24:496-502.

$\mathrm{He} \mathrm{QH}$, Wang R, Wang WW, et al. Effect of particle size distribution of petroleum coke on the properties of petroleum coke-oil slurry. Fuel. 2011;90(9):2896-901.

Milenkova KS, Borrego AG, Alvarez D, et al. Devolatilisation behaviour of petroleum coke under pulverised fuel combustion conditions. Fuel. 2003;82(15-17):1883-91.

Mishra SK, Senapati PK, Panda D. Rheological behavior of coalwater slurry. Energy Sources. 2002;24(2):159-67.

Roh NS, Shin DH, Kim DC, et al. Rheological behavior of coal-water mixtures. 1. Effect of coal type, loading and particle-size. Fuel. 1995a;74(8):1220-5.

Roh NS, Shin DH, Kim DC, et al. Rheological behavior of coal-water mixtures. 2. Effect of surfactants and temperature. Fuel. 1995b;74(9):1313-8.

Vitolo S, Belli R, Mazzanti M, et al. Rheology of coal-water mixtures containing petroleum coke. Fuel. 1996;75(3):259-61.

Wang JS, Anthony EJ, Abanades JC. Clean and efficient use of petroleum coke for combustion and power generation. Fuel. 2004;83(10):1341-8.

Wang RK, Liu JZ, Yu YJ, et al. The slurrying properties of coal water slurries containing raw sewage sludge. Energy Fuels. 2011;25(2): $747-52$.

Wang ZQ, Wang HF, Guo QJ. Effect of ultrasonic treatment on the properties of petroleum coke oil slurry. Energy Fuels. 2006;20(5):1959-64.

Wildemuth CR, Williams MC. Viscosity of suspensions modeled with a shear-dependent maximum packing fraction. Rheol Acta. 1984;23(6):627-35.

Wu YQ, Wu SY, Gu J, et al. Differences in physical properties and $\mathrm{CO}_{2}$ gasification reactivity between coal char and petroleum coke. Process Saf Environ Prot. 2009;87(5):323-30.

$\mathrm{Xu} \mathrm{RF}, \mathrm{He} \mathrm{QH}$, Cai J, et al. Effects of chemicals and blending petroleum coke on the properties of low-rank Indonesian coal water mixtures. Fuel Process Technol. 2008;89(3):249-53.

Yang BL, Gong KF, Zou JJ, et al. Slurryability of lignite and petroleum coke mixture. J Fuel Chem Technol. 2008;36(4): 391-6 (in Chinese). 
Yu YJ, Liu JZ, Wang RK, et al. Effect of hydrothermal dewatering on the slurryability of brown coals. Energy Convers Manag. 2012;57:8-12.

Zhan XL, Zhou ZJ, Kang WZ, et al. Promoted slurryability of petroleum coke-water slurry by using black liquor as an additive. Fuel Process Technol. 2010;91(10):1256-60.

Zhan XL, Jia J, Zhou ZJ, et al. Influence of blending methods on the co-gasification reactivity of petroleum coke and lignite. Energy Convers Manag. 2011;52(4):1810-4.
Zhou ZJ, Hu QJ, Liu X, et al. Effect of iron species and calcium hydroxide on high-sulfur petroleum coke $\mathrm{CO}_{2}$ gasification. Energy Fuels. 2012;26(3):1489-95.

Zhu SQ, Zou LZ, Huang B, et al. Study on the interaction characteristics between different CWS dispersants and coals I. Effect of the interaction of complex coal particles on CWS rheological behavior. J Fuel Chem Technol. 2003;31(6):519-24 (in Chinese). 